\title{
Makroekonomik Değişkenlerin Finansal Kırılganlık Üzerine Etkisi
}

\section{Esra ATUKALP 1}

Özet

Finansal kırılganlıkların reel sektör üzerinde olumsuz etkilere de neden olabilmesi nedeniyle bu kırılganlıkların öngörülmesi ve önlenebilmesi yönünde çaba sarf edilmesini ve bu amaçla da finansal kırılganlıklarım ele alınmasını gerekli kılmaktadır. Bu çalışmanın amacı, Türkiye'de kredi temerrüt takası, reel efektif döviz kuru, faiz oranı ve enflasyonun finansal kırllganlık üzerine etkisini belirlemektir. Çalışmada, söz konusu ilişski 2009:Q1-2020:Q4 dönemi için gecikmesi dağıtılmış otoregresif model (autoregressive distributed lag - ARDL) yaklaşımı kullanılarak araştırılmıştır. Analiz sonucuna göre, kredi temerrüt takası, döviz kuru ve enflasyonun hem kisa hem de uzun dönemde Türkiye'deki finansal kırılganlı̆̆ı pozitif etkilediği, faiz oranının ise sadece uzun dönemde pozitif etkilediği, kısa dönemde ise herhangi bir etkisinin olmadığı tespit edilmiştir. Buna göre kredi temerrüt takasının, döviz kurunun, faiz oranının ve enflasyonun artmasının finansal kırılganlı̆̆ı artırması söz konusu olmaktadır.

Anahtar kelimeler: Finansal kırılganlık, Türkiye, kredi temerrüt takası, döviz kuru, faiz oranı, enflasyon. Jel Kodu: C22, G17, G21

\section{The Effect of Macroeconomic Variables on Financial Fragility}

\begin{abstract}
The fact that the financiak fragilities may also have negative effects on the real sector requires efforts to anticipate and prevent fragilities in the banking sector and to address financial fragilities for this purpose. The aim of this study is to determine the impact of credit default swaps, real effective exchange rate, interest rate and inflation on financial fragility in Turkey. In the study, the aforementioned relationship is investigated by using autoregressive distributed lag (ARDL) approach for the period 2009:Q1-2020:Q4. According to the results of the analysis, it has been determined that credit default swap, exchange rate and inflation have a positive effect on financial fragility in Turkey both short and long term, while the interest rate has a positive effect only in the long term and has no effect in the short term. Accordingly, the increase in credit default swap, exchange rate, interest rate and inflation increase financial fragility.
\end{abstract}

Keywords: Financial fragility, Turkey, credit default swap, exchange rate, interest rate, inflation.

Jel Codes: C22, G17, G21

\section{GİRİş}

Bankacılık sektörü, büyüklüğü ve fonksiyonları itibariyle finans sisteminin en büyük parçası durumundadır. Bu sebeple sektörde meydana gelebilecek genişleme ve daralma finansal istikrar açısından önem arz etmektedir. Bankacılık sektörü kaynaklı kırılganlıkların, finansal sistemin tamamina yaylabilmesi ve reel sektör üzerinde olumsuz etkilere neden olabilmesi, bankacılı sektörüne ilişkin kırılganlıkların öngörülmesi ve önlenebilmesi yönünde çaba sarf edilmesi noktasında finansal kırılganlıkların ele alınmasını gerekli kılmaktadır.

Finansal serbestleşme, finansal piyasalar ve ticaret hacmi gibi ekonominin her alanında dönüşüme neden olmuştur. $\mathrm{Bu}$ doğrultuda finansal sistemin büyümesi söz konusu olmuş ve finansal sistemde gerçekleşen bu büyüme ile finansal kırılganlık kavramı önem kazanmıştır.

Finansal serbestleşmenin spekülasyon kaynaklı ekonomik kalkınmaya yol açabileceği, büyük bir finansal kriz olasılığına, bir yanlış kredi tahsisine ve nihayetinde reel sektör ekonomik büyüme oranlarının düşmesine

ATIF ÖNERİsí (APA): Atukalp, M. Esra. (2021). Makroekonomik Değişkenlerin Finansal Kırılganlık Üzerine Etkisi. İzmir İktisat Dergisi. 36(3). 695-708. Doi:10.24988/ije.202136313

${ }^{1}$ Dr. Öğr. Üyesi, Giresun Üniversitesi, Bulancak K.K. Uygulamalı Bilimler Yüksekokulu, Uluslararası Ticaret ve Finansman Bölümü, Bulancak / GİRESUN, EMAIL: esra.atukalp@gmail.com ORCID:0000-0001-8412-1448 
neden olması (Grabel, 1997: 111) ihtimalinden bahseden çalışmalar finansal kırılganlığın incelenmesi konusunda araștırmalara neden olmaktadır. Finansal kırılganlık gerek finansal kuruluşlara ilişkin göstergeler gerekse ülkelerin makro ekonomik göstergeleri baz alınarak incelenmektedir. Burada finansal kurumların mali tablolarından elde edilen içsel göstergelerin ve makroekonomik göstergelerin finansal kırılganlıkla bağlantısının ele alınması ve bu kapsamda kırılganlığın önlenmesi noktasında karar alanı olușturulabilmesi söz konusu olabilmektedir.

$\mathrm{Bu}$ çalışmanın amacı, Türkiye'de kredi temerrüt takası, reel efektif döviz kuru, faiz oranı ve enflasyonun finansal kırılganlık üzerine etkisini belirlemektir. Çalışmanın tarihsel olarak yakın dönemi incelemesi ve bağımsız değișken olarak bankacılığa özgü değişkenlerin değil, makro ekonomik göstergelerin ele alınarak makro düzeyde analizin yapılması çalışmanın özgün değeri olarak ele alınabilir. $\mathrm{Bu}$ kapsamda bir ekonomiyi bir bütün olarak ele alarak makro ekonomik göstergelerle kırılganlık arasındaki ilişkinin ortaya konulmasının önemi gözlenmektedir. Analizin yapıldı̆̆ı yöntem olan ARDL yöntemi, gerek değişkenlerin durağanlıklarının farklı düzeylerde olması durumunda değişken ilişkisinin araştırılmasını mümkün kılması gerekse küçük örneklerde daha etkili olması ile kısa ve uzun dönem dinamiklerinin birlikte dikkate alınabilmesi nedeniyle tercih edilmektedir.

Finansal varlık fiyatlarını ve yatırımları, kredi temerrüt takası primi vasıtası ile gözlemlenebilen ülke riskinin etkileyebilmesi ve yatırım kararlarında ülke riskinin analizinin önemi, finansal istikrar ve kırılganlık analizlerinde kredi temerrüt takası değişkeninin ele alınmasında etkili olmaktadır. Öte yandan reel döviz kuru endeksinin, ulusal paranın yabancı paralar karşısında değer kazanma / kaybetme düzeyini göstermesi bakımından önemli bir öncü gösterge olması ve enflasyon değişkeninin de fiyatlar genel düzeyindeki değişikliği göstermekte olması ve önemli makroekonomik değişkenler arasında yer alması çalışmada açıklayıcı değişkenler olarak belirlenmelerinde etkili olmuştur.

Çalışma giriş kısmı ile birlikte beş bölümden oluşmaktadır. İkinci bölümde finansal kırılganlıkla ilgili kavramsal çerçeveye yer verilmiştir. Üçüncü bölümde finansal kırılganlığın farklı değișkenler ve analiz yöntemleri temelinde ele alındığı literatür çalışmaları incelenmiş ve değerlendirilmiştir. Dördüncü bölümde Türkiye'de finansal kırılganlığın dinamikleri analiz edilmiş olup bu kapsamda ilgili bölümde analizde kullanılan yöntemler ile veri seti açıklanmış ve analiz bulgularına yer verilmiştir. Beşinci bölümde ise çalışmanın sonuç bölümü yer almaktadır.

\section{FINANSAL KIRILGANLIK}

Kırılganlık, ekonomik ve finansal kırılganlık olmak üzere iki başlık altında incelenebilir. Ekonomik kırılganlık için bir ekonomide yükümlülüklerin yerine getirilmesi hususunda meydana gelen bazı aksamaların sistemde büyük değişimlere neden olması ve sistemin kendini toparlayamaması ifadesinde bulunulabilir (Tokucu, 2012: 197). Öte yandan bir iktisadi birimin finansal yapısının kırılganlığı, iktisadi birimin elde edeceği nakit akımları ile yükümlülüklerine bağlı olarak belirlenmekte ve nakit akımlarının yükümlülüklerini karşılamaya yeterli olmayan yapıların kırılgan olduğu söylenebilmektedir (Minsky, 1995: 8-9).

Ekonomik kırılganlık, kırılganlık riski taşıyan ekonomik birime göre mikroekonomik ve makroekonomik kırılganlık olmak üzere ikiye ayrılmaktadır. Ekonomik dalgalanma ve şokların etkilerini hane halkı düzeyinde mikroekonomik bazda inceleyen mikroekonomik kırılganlık; hane halkının yoksunluğuna, hastalık ve işsizlik gibi kendine özgü risklere ve hatta ortak değişken olarak tanımlanan mahsul değişikliklerine ve doğal olaylara karşı kırılganlığa değinmektedir (Andrews ve Flores, 2008: 2). Ekonomik kırılganlık, ekonomik dalgalanma ve şokların 
etkilerini hane halkı düzeyinde mikroekonomik bazda incelenirken; şok ve dalgalanmaların etkilerini, enflasyon, ișsizlik, büyüme oranları, borç stoku gibi temel ekonomik göstergeler üzerinden makroekonomik anlamda incelenmektedir. Bireyleri değil, bir ülkeyi veya ekonomiyi bir bütün olarak ele almakta olan makro ekonomik kırılganlık, bir ülkenin özellikleri ve yapısı nedeniyle ortaya çlkabilmekte ve uygulanan politikalar da bunda belirleyici olabilmektedir (Mete, Pekmez ve Kıyançiçek, 2016: 691).

Makroekonomide finansal kırılganlık terimi, bir finansal sistemin küçük rutin şokların neden olduğu büyük ölçekli finansal krizlere duyarlılığına atıfta bulunmak için kullanılmaktadır (Lagunoff ve Schreft, 2001: 220). Finansal kırılganlık, sıradan ve günlük ekonomik kargaşanın büyük ölçekli ekonomik ve finansal krize neden olmasına izin vermekte olan finansal sistemin kırılganlı̆̆ını ifade etmektedir. Finansal kırılganlığın, finansal liberalizasyondan, hatalı politika uygulamalarından, diş şoklardan, politik istikrarsızlıklardan ve asimetrik bilgiden kaynaklandığı bilinmektedir (Şimşek, Hazar ve Babuşçu, 2019: 53). Finansal olarak kırılgan bir yapı, bankacılık sisteminin zayıflamasına, dışsal şoklara karşı finansal sistemin ve ekonominin savunmasız kalmasına neden olabilmektedir. $\mathrm{Bu}$ nedenle finansal krizlerin finansal sisteme etkilerini azaltmak için finansal kırılganlığın ölçülmesi ve kırılganlığı etkileyen faktörlerin belirlenmesi önemlidir (Topaloğlu, 2018: 16).

Kırılganlığın nedenleri arasında çalışma konuları ile bağlantılı olarak kaynaklarda farklı açıklamalara ulaşmak mümkündür. $\mathrm{Bu}$ doğrultuda kırılganlığın nedenlerine ilişkin düşüncelerin ifadesi olarak ileri sürülen kırılganlık endeksine ilişkin çalışmalar incelendiğinde kırılganlığın bileșenlerinden bir kısmı, dış ekonomik koşullara açıklık, ticari açıklık, sermaye açıklığı, enerjiye bağımlılık, turizme bağımlılık, mal ve hizmet ihracatında istikrarsızlık, tarımsal üretimde istikrarsızlık, doğal afetlere meyil, nüfus büyüklüğü, reel kur endeksi olarak ele alınmaktadır (Mete ve diğerleri, 2016: 693-694).

\section{LITERATÜR İNCELEMESİ}

Türkiye bankacılı sektöründe finansal kırılganlığın ele alındığı çalışmalar makro ekonomik değișkenlerin belirleyiciliğinin ve bankaya özgü değişkenlerin belirleyiciliğinin araştırılması noktasında farklılaşmaktadır. Uluslararası literatürde finansal kırılganlık üzerine yapılan çalışmalar banka denetimi, bankaya özgü değişkenler ve makro ekonomik incelemeler içermektedir. Gerek makro ekonomik gerekse bankaya özgü değişkenlerin finansal kırılganlık üzerine etkisinin incelendiği çalışmalardan bir kısmı aşağıda ele alınmıştır.

Demirgüç Kunt ve Detragiache (1997), çok değişkenli bir logit ekonometrik model kullanarak, 1980-1994 yıllarında geniş bir gelişmiş ve gelişmekte olan ülke örnekleminde sistemik bankacılı krizlerinin ortaya çıkmasıyla ilişkili faktörleri incelemişlerdir. Analiz sonucunda makroekonomik ortam zayıflığının krizlere sebebiyet verdiğini belirlenmiştir. Özellikle düşük gayrisafi yurtiçi hasıla (GSYIH) büyümesi ve yüksek enflasyonun varlığının krizlere neden olan ve finansal kırılganlığı artıran bir unsur olduğu, yüksek reel faiz oranlarının da sistemik bankacılık sektörü sorunları ile açıkça ilişkili olduğu ve ödemeler dengesi krizlerine karşı kırllganlığın bir rolü bulunduğu belirtilmektedir.

Penas ve Alkan (2010), finansal kırılganlık göstergeleri kötüleșen Türk bankalarının 2000/2001 krizine yol açan yıllarda piyasa izlemesine tabi olup olmadığını ve piyasaya aktarılan bilgilerin kalitesi ve zamanında olmasının piyasa tepkisini nasıl etkilediğini, 1995-2001 yılları arasında İstanbul Menkul Kıymetler Borsası'nda işlem gören 12 ticari Türk bankasını kapsamında panel veri analizi ile incelenmiștir. Çalışmada piyasaya aktarılan bilgilerin kalitesi ve zamanında olmasının piyasa tepkisini nasıl etkilediği de araştırılmıștır. Analiz sonucunda hissedarların, vade uyumsuzluklarındaki artışlar, para birimi uyumsuzlukları ve takipteki krediler gibi 
finansal kırılganlık göstergelerine olumsuz tepki verdiğini ve hissedarların finansal kırılganlık göstergelerinin gelecekteki kârlar üzerindeki etkisine ilişkin endişelerini gösterdikleri belirlenmiştir. Denetim raporlarının açıklanmasında gecikme yaşanmasının bilgilendirici olmadığını ve zamanlamalarını iyileștirme ihtiyacının gerekliliği belirtilmektedir. Son olarak, çalışmada menkul kıymet fiyatlarının finansal kırılganlık göstergelerine tepki verdiği bulgusunun, bankaların güvenlik ve sağlamlığının yeterli kanıtı olarak alınmaması gerektiği belirtilmektedir. Klomp ve Haan (2015), gelişmekte olan 94 ülkede bulunan 1238 bankaya ait 2002-2008 dönemi verileri kullanarak, banka düzenlemesi ve denetiminin bankacılık finansal kırılganlıkları (riski) üzerindeki etkisinin banka yapısına bağlı olup olmadığını araştırmışlardır. Çalışma sonucunda özellikle sermaye yeterliliğinin ve denetim kontrolünün bankacılıkta riski azalttı̆̆ı, düzenleme ve denetimin diğer boyutlarının etkinliğinin bankaların organizasyon yapısına bağlı olduğu belirtilmiştir.

Fielding ve Rewilak (2015) hem finansal kırılganlığın ve hem de aşırı derecede kredi verilmesinin, bir bankacılık krizi olasılığının önemli belirleyicileri olduğu ifadesi ile, sermaye girişindeki artışların, aşırı derecede kredi verilmesinin ve finansal kırılganlığın bankacılık krizi olasılığı üzerindeki etkisini araştırmışlardır. Çalışmada 121 ülkeden 956 bankanın 1999-2011 dönemi verileri panel veri analizi ile ele alınmıștır. Analiz sonucunda aşırı derecede kredi verilmesinin kriz olasılığını yalnızca nispeten kırılgan finansal sistemlerde artırdığ ifade edilmektedir. Iftikhar (2015) son dönemdeki bankacılık krizi dalgalarının, temel olarak yüksek bir kredi temerrüt oranına bağlanması nedeniyle finansal reform politikalarının finansal kırılganlık üzerindeki etkisini incelemek amacıyla yaptığı çalışmada, 2001-2005 döneminde 779 bankadan oluşan bir örneklem için banka düzeyinde verileri kullanarak 76 gelişmiş ve gelişmekte olan ülke için finansal kırılganlığın belirleyicilerini araştırmıştır. Bankaların finansal kırılganlığını etkileyebilecek, reform ve düzenleme göstergelerinin yanı sıra, ele alınan ülkelerin finansal kırılganlığının hem bankaya özgü hem de makroekonomik belirleyicilerini ele almıştır. Bu değişkenler finansal kırılganlığın bir göstergesi olarak değer düşüklügüne uğramış kredilerin brüt kredilere oranı, özkaynak varlık oranı, brüt kredilerin büyümesi, toplam varlıkların logaritması, banka verimliliğinin bir göstergesi olarak gider / gelir oran, bankaların mülkiyet modeli ve makroekonomik kontrol değişkenleri olarak da GSYIH büyümesi, işsizlik oranını ve GSYIH deflatörü olarak sıralanabilir. Bu çalışmanın ampirik bulguları, finansal reformların ve finansal serbestleşmenin finansal kırılganlık olasılığını önemli ölçüde artırdığına, güçlü ve sağlam bankacılık düzenlemeleri ve denetimin finansal kırılganlığı azalttığı yönündedir. Öte yandan, kredi büyümesi ve işsizliğin gecikme değerinin finansal kırılganlığı artırdığı, özkaynak aktif oranı ve toplam aktiflerin büyüklügünün ve yabancı bankaların payının finansal kırılganlığı azalttığı belirlenmiştir.

Kinda, Mlachila ve Ouedraogo (2016), emtia fiyatlarındaki şokların finansal sektör kırılganlığı üzerindeki etkisini araştırmışlardır. Panel veri analizi ile yapılan çalışmada, banka tahsili gecikmiş krediler, tahsili gecikmiş kredi karşılıklar, aktif kârlılığı, özkaynak kârlılığı, gider / gelir oranı, likit varlıklar, risk ağırlıklı varlıklar için düzenleyici sermaye olarak sıralanan yedi finansal istikrar göstergesi kullanılmıştır. 1997-2013 döneminde gelişmekte olan ekonomiler arasında yer alan 71 emtia ihracatçısından oluşan bir örneklemi kullanarak yapılan çalışmada, emtia fiyatlarına yönelik olumsuz şokların, yüksek finansal sektör kırılganlığı ile ilişkili olduğu ifade edilmektedir. Çalışma sonucunda ayrıca emtia fiyat şokları sistemik bankacılık krizi olasılığını artırmakta olduğu da belirtilmektedir. Demirel, Barışık ve Karanfil (2016) tarafından gerçekleștirilen ve 2010-2015 döneminde Türk bankacılık sektörünün finansal kırılganlığını 
etkileyen faktörlerin analiz edildiği çalışmada sektörünün kırılganlığını temsil etmek amacıyla genişletilmiş bankacıllk sektörü kırılganlık endeksi, bağımsız değișkenler olarak ise tüketici fiyat endeksi, reel döviz kuru, sanayi üretim endeksi, Türkiye Cumhuriyet Merkez Bankası politika faiz oranı, takipteki krediler, Chicago Borsası Opsiyon Borsası volatilite endeksi, ABD 2 ylllk hazine bonosu faizi modele dahil edilmiştir. Çalışmada değişkenler arasındaki kısa ve uzun dönem ilişkiler analiz edilmiş olup, Johansen eşbütünleşme yöntemi ve hata düzeltme modeli kullanılmıștır. Analiz sonucunda Türk bankacllı sektöründe kırılganlığın artmasına yol açan temel etmenler olarak takipteki kredilerdeki artış ve küresel faktörlerdeki olumsuz gelişmeler olarak belirtilmiştir. Öte yandan analiz sonucunda reel döviz kuru, enflasyon, takipteki krediler / toplam krediler, Merkez Bankası politika faiz oranı, volatilite endeksi ve Amerika Birleşik Devletleri (ABD) Merkez Bankası politikasındaki değişmeleri gösteren gösterge olarak ABD 2 yıllık hazine bonosu ile banka kırlganlık endeksi arasında pozitif, sanayi üretim endeksi ile banka kırılganlık endeksi arasında ise negatif ilişkiye rastlanmıștır. Türk bankacllık sektörünün dış finansman bağımlısı olması ile küresel faktörlerin Türk bankacıllk sektörü kırılganlığı üzerindeki güçlü etkisi bağlantılı olarak yorumlanmıştır.

Kaya ve Köksal (2018)'ın kredi riskinin bankacıllı sektörü finansal kırılganlığı üzerindeki etkisini belirlemek amacıyla yapılan çalışmalarında analiz dönemi olarak Ocak 2003-Nisan 2018 dönemi ele alınmıştır. Analizde bağımlı değişken olan takipteki kredilerin toplam kredi oranı finansal kırılganlık göstergesi olarak, bağımsız değişken olarak ise kredi risk göstergesi olan kredi temerrüt takası belirlemiştir. İlgili değişkenler arasındaki nedensellik ilişkisini belirlemek için Granger nedensellik analizi, değişkenler arasında ikili ilişkilerin belirlenmesinde ise regresyon analizi tahmin edilmiştir. Analiz sonucunda kredi riskinden finansal kırılganlığa doğru tek taraflı nedensellik olduğu ve ayrıca kredi riskinde meydana gelen artışın finansal kırılganlığ artırdığ söylenmiştir. Topaloğlu (2018), Türkiye bankacillk sektöründe 20022015 döneminde devamlı faaliyet gösteren mevduat bankalarının finansal kırılganlıklarına etki eden mikro faktörleri belirlemeye çalışmıştır. Takipteki kredi oranı ve sermaye yeterlilik oranı ile finansal kırılganlığın temsil edildiği çalışmada; özsermaye kârlılığı, aktif kârlılığı, likidite oranı, finansal kaldıraç, banka büyüklüğü ve net faiz marjı ise mikro faktörler olarak belirlenmiştir. Analizde panel veri analizi yöntemi kullanılmıştır. Sonuç olarak, takipteki kredi oranı ile banka büyüklüğü arasında negatif, likidite oranı ile pozitif ilişki tespit edilmiştir. Sermaye yeterlilik oranı ile net faiz marjı ve aktif kârlılık oranı arasında pozitif, özsermaye kârlılığı ve finansal kaldıraç ile negatif ilişki tespit edilmiştir. Çalışmada öte yandan, bankacıllk sektörünün kırılgan bir yapıya sahip olmadığı ve incelenen dönem içerisinde gerçekleșen finansal krizlerin olumsuz sonuçlarıyla bağlantılı olarak daha ihtiyatlı davrandığı ileri sürülmektedir.

Bölükbaşı, Ürkmez ve Karamustafa (2018) Türkiye'de bankacilık kırılganlık endeksi ve ekonomik aktivite arasındaki ilişkiyi analiz etmeyi amaçladıkları çalışmalarında 20052016 dönemini ele almışlardır. Türkiye'nin bankacllık sektörünün kırılganlığının analiz edildiği bu çalışmada kırılganlık endeksi takipteki alacakların toplam kredilere oranı, sermaye yeterliliği oranı ve dönem net kâr veya zararın özkaynaklara oranı serilerinden oluşturulmuș, ekonomik aktivite için sanayi üretim endeksi büyüme oranı ele alınmıștır. Analizde Granger nedensellik analizi ve değişkenler arasındaki dinamik ilișkinin tespiti için vektör otoregresif (VAR) modeli kullanılmıştır. Analizde, kırılganlık endeksinin ekonomik aktivite (Sanayi üretim endeksinin) üzerinde önemli bir etkisinin olmadığı ancak ekonomik aktivitenin kırılganlık endeksine etki ettiği, reel ekonomide yaşanan daralmanın kırılganlık endeksini yükselteceği tespit edilmiş olup, küresel finansal krizin de etkisi ile 2008 yılında reel ekonomideki daralma sonucu birkaç dönem gecikme ile birlikte bankacillk sektörünün kırılganlığının yükseldiği ifade 
edilmektedir. Şimşek ve diğerleri (2019), Türkiye için ülke kırılganlık skoru ile işsizlik oranı, büyüme oranı, enflasyon oranı ve ihracatın ithalatı karșılama oranı arasındaki nedensellik ilişkisini, 2006 ve 2018 dönemi kapsamında incelenmişlerdir. Analizde eşbütünleşme analizi, Granger nedensellik analizi, hata düzeltme modeli yöntemlerinden yararlanılmıştır. Analiz sonucunda, kırılganlığın işsizlik oranı ve enflasyon oranı ile uzun dönemli anlamlılığı belirlenmiştir; analiz sonuçlarına göre enflasyon kırılganlığın nedeni olup, enflasyonun etkisi sonucu Türkiye'de kırılganlık görülmektedir, fakat işsizliğin kırılganlığın nedeni olmamasına karşın kırılganlığı etkilediği belirlenmiştir.

Erdoğdu (2019), bankacılık sektöründe finansal kırılganlığı makro ve mikroekonomik ve bankacılık sektörüne özgü koşulları içeren birçok faktörün oluşturabileceği düşüncesi ile banka bilançosunda yer alan ve sektöre özgü olan değişkenlerle Türk bankacılık sektöründe, finansal kırılganlık etkisini, 2007-2018 dönemi için analiz etmiştir. Analizde panel veri analizi yöntemi kullanılmıştır. Analiz sonucunda, yoğunlaşma ve sermaye yeterliliğinin, finansal kırılganlık için en önemli değişkenler olduğu belirtilmiştir. Akkaya ve Kantar (2019), Türk bankacılık sektörünün kırılganlık yapısını 1996-2017 döneminde Logit / Probit modeller ile incelemişlerdir. Analiz sonucunda açıklama gücü en yüksek olan modelde Logit yöntemine göre döviz kuru ve mevduat faizi değişkenlerinin, Probit yöntemine göre döviz kuru, kredi tutarı/mevduat tutarı ve mevduat faizi değişkenlerinin anlamlılığ edilmiştir. Balıkçıoğlu (2020) Türkiye ve Balkan ülkelerinin makroekonomik kırılganlığını 2007-2017 dönemi için karşılaştırmalı olarak analiz etmiştir. Makroekonomik kırılganlığı ölçmek için mali kırılganlık, finansal kırılganlık ve dış kırılganlık olarak sıralanan değișkenleri ele alınmıștır. Analiz sonucunda, Türkiye ekonomisinde kırılganlığa yol açan unsurların dış kırılganlık ve finansal kırılganlık olduğu belirlenmiștir. Bulgaristan dış kırılganlık ve mali kırılganlığı,
Kosova mali kırılganlık ve finansal kırılganlığı en az olan ülkeler olarak belirlenmiş olup, Yunanistan dış kırılganlık, mali kırılganlık ve finansal kırılganlığı ile incelenen ülkeler arasında en kırılgan ülke konumundadır.

\section{TÜRKIYE'DE FINANSAL KIRILGANLIĞIN DİNAMİKLERİNİN ANALİZİ}

Literatürde yer alan çalışmalar incelendiğinde de görüldüğü üzere Türkiye'de finansal kırılganlığın analizi gerek bankaya özgü değişkenlerin finansal kırılganlık ile ilişkisi kapsamında gerekse makro ekonomik birtakım değişkenlerin ele alınması sureti ile gerçekleştirilmiştir. Ancak veri setinin

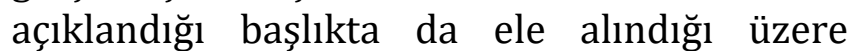
literatürde bir bütün olarak yer almadığı belirlenen kredi temerrüt takası, reel efektif döviz kuru, faiz oranı ve enflasyonun finansal kırılganlık üzerine etkisi bu başlık altında incelenecektir.

\subsection{Yöntem ve Veri Seti}

Çalışmada kredi temerrüt takası, reel efektif döviz kuru, faiz oranı ve enflasyonun finansal kırılganlı üzerine etkisinin incelenmesi amaçlanmaktadır. Bu bölümde, değişkenlerin durağanlık seviyelerinin belirlenmesinde kullanılan birim kök testleri, eşbütünleşme ilişkisini ortaya koyan ARDL sınır testi yaklaşımı (gecikmesi dağıtılmış otoregresif model - autoregressive distributed lag) ve veri seti ele alınmıştır.

\subsubsection{Birim Kök Testleri}

Değişkenlerin durağanlık seviyeleri Ng-Perron birim kök testleri ile belirlenmiştir. Ng-Perron (2001), Phillips-Perron testi için geliştirilen ve bu testlerde ortaya çlkan hata terimlerinde mutlak anlamda büyük negatif işaretli AR (Autoregressive Process - Otoregresif Süreç) ve MA (Moving Average Process- Hareketli Ortalama Süreci) kökleri durumlarında hata terimlerindeki boyut dağılım bozukluğunu düzeltmek için geliştirilen birim kök testleridir. Ng-Perron GLS (Generalized Least Squares Genelleştirilmiş En Küçük Kareler) trendden arındırma prosedürünü $\mathrm{y}_{T}^{d}$ kullanan dört test 
istatistiği kullanarak durağanlık seviyelerini belirlemişlerdir (Yamak ve Erdem, 2017: 116). Kullanılan test istatistikleri dört ayrı birim kök testinden oluşmaktadır (Göktaş, 2008: 53).

Ng-Perron birim kök testinde ilk test istatistiği, $M Z_{\alpha}^{d}$ test istatistiği (1) ve (2) no'lu denklemde gösterilmektedir.

$M Z_{\alpha}^{d}=\left(\mathrm{T}^{-1}\left(\mathrm{y}_{T}^{d}\right)^{2}-f_{0}\right) /(2 k)$

$M Z_{t}^{d}=M Z_{\alpha} \times \mathrm{MSB}$

(1) ve (2) no'lu denklemlerdeki $M Z_{\alpha}^{d}$ ve $M Z_{t}^{d}$ istatistiklerinin $\mathrm{H}_{0}$ hipotezi birim kökün varlığını göstermektedir.

Ng-Perron birim kök testinde kullanılan $\mathrm{MSB}^{\mathrm{d}}$ test istatistiği (3) no'lu denklemde gösterilmiştir. (3) no'lu denklemdeki $M S B^{d}$ istatistiğinin $\mathrm{H}_{0}$ hipotezi birim kökün yokluğunu göstermektedir.

$M S B^{d}=\left(\frac{K}{f_{0}}\right)^{1 / 2} \quad K=\sum_{t=2}^{T}\left(\mathrm{y}_{t-1}^{d}\right)^{2} / T^{2}$

Ng-Perron birim kök testinin son test istatistiği ADF-GLS (Augmented Dickey - Fuller Generalized Least Squares) testinin modifiye edilmiş şekli olan $M P_{T}^{d}$ testinde iki durum söz konusudur. İlk durum sadece sabit diğeri ise hem sabit hem trend durumunun olmasidır. Parametre c, sabitlerde -7 , sabit ve trendlilerde -13.5'dir (Yamak ve Erdem, 2017: 116).

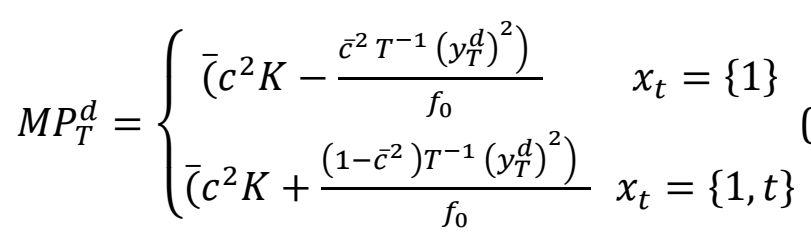

$\bar{c}=\left\{\begin{array}{cl}-7 & x_{t}=\{1\} \\ -13,5 & x_{t}=\{1, t\}\end{array}\right.$

(4) no'lu denklemdeki $M P_{T}^{d}$ istatistiğinin $\mathrm{H}_{0}$ hipotezi birim kökün yokluğunu göstermektedir.

\subsubsection{Veri Seti}

Kırılganlığın göstergesi olarak hizmet edebilecek potansiyel olarak çok sayıda değişken bulunmaktadır. Finansal krizlerin temelinde finans sektöründeki zayıflıkların yattığı algısından yola çıkarak, özel sektör kredi büyümesi, finansal serbestleşme önlemleri, bankacılık sisteminin kısa vadeli dış borçluluk düzeyi, yurt içi faiz oranlarının yapısı gibi değişkenler, hisse senedi fiyatlarındaki değișimler, tahsili gecikmiș kredilerin kapsamı ile ölçülen banka varlıklarının kalitesi vb. gösterge olarak kullanılabilir (International Monetary Fund [IMF], 1998: 88). Çalışmada finansal kırılganlık göstergesi olarak, finansal kırılganlığın mevcut en iyi ölçüsü olduğu (Rinaldi ve Sanchis-Arellano, 2006: 28) öne sürülmekte olan, takipteki kredilerin toplam kredilere oranı ele alınmıştır.

Kredi temerrüt takası (Credit Default SwapCDS), koruma alıcısının, sözleşme süresi içinde referans varlığı içeren bir kredi olayının meydana gelmesi durumunda, koşullu bir ödeme karşılığında koruma satıcısına periyodik bir prim / ücret ödediği ikili bir finansal sözleşmedir (Brandon ve Fernandez, 2005: 56). Diğer bir ifade ile CDS koruma alıcısının (risk satıcısı), belirli bir referans kurumun ihraç ettiği tanımlanmış referans varlıkların temerrüde düșme riskini, koruma satıcısına (risk alıcısı) periyodik prim ödemeleri karşılığında transfer ettiği bir sözleşmedir. Söz konusu tarafların CDS kullanma nedenleri; kredi riskini alarak ek getiri artışı sağlamak, kredi riskini transfer etmek, portföy çeşitlendirmesi yapmak veya belirli bir müşterinin kredi limitini artırmak olabilir (Karabıyık ve Anbar, 2006: 2). CDS primlerdeki artış veya azalışlar, referans varlığın değerindeki değișikliklere bağlıdır. Ülke CDS primlerindeki bu değişimler uluslararası yatırımcılar için oldukça önemlidir (Çizgici Akyüz ve Akbulut Bekar, 2021: 166). CDS primi vasıtası ile gözlemlenebilen ülke riskinin finansal varlık fiyatlarını ve yatırımları etkileyebilmesi, yatırım kararlarında ülke riskinin analizinin önemi ve CDS piyasasında yaşanan hızlı gelişmeler (Bozkurt, 2015: 66) finansal istikrar ve kırılganlık analizlerinde CDS değişkeninin ele alınmasında etkili olmaktadır.

Nominal efektif döviz kuru Türk lirasının, Türkiye'nin dış ticaretinde önemli paya sahip ülkelerin para birimlerinden oluşan sepete göre, ağırlıklı ortalama değeri olarak 
tanımlanmaktadır. Reel efektif döviz kuru ise nominal efektif döviz kurundaki nispi fiyat etkileri arındırılarak elde edilmektedir (Türkiye Cumhuriyet Merkez Bankası [TCMB], 2021). Reel döviz kuru endeksi, ulusal paranın yabancı paralar karşısında ne ölçüde değer kazandığını / kaybettiğini göstermesi bakımından önemli bir öncü göstergedir (Çakmak, 2013: 244). Analizde kullanılan fiyatlar genel düzeyindeki değişikliği gösteren enflasyon değişkeni ile mevduat faiz oranı (3 aya kadar vadeli-TL) önemli makroekonomik değişkenler arasında yer almaktadır.

Türkiye'de 2009:Q1-2020:Q4 dönemi için finansal kırılganlık ile kredi temerrüt takası, döviz kuru, faiz oranı ve enflasyon arasındaki ilişkinin analiz edildiği çalışmada finansal kırılganlığı temsilen takipteki kredilerin toplam krediler içindeki payı, kredi temerrüt takası için Turkey CDS USD SR 5Y ve TÜFE bazlı reel efektif döviz kuru kullanılmış ve değişken tanımları Tablo 1'de gösterilmiştir.

Tablo 1: Değişken Tanımları

\begin{tabular}{|c|c|c|}
\hline Değişken & Açıklama & Kaynak \\
\hline FIK & $\begin{array}{c}\text { Finansal Kırılganlık (Takipteki } \\
\text { Krediler / Toplam Krediler) }\end{array}$ & BDDK \\
\hline CDS & Kredi Temerrüt Takası & Bloomberght \\
\hline D & $\begin{array}{c}\text { Reel Efektif Döviz Kuru } \\
\text { (Tüfe Bazlı) }\end{array}$ & TCMB EVDS \\
\hline F & Mevduat Faiz Oranı & TCMB EVDS \\
\hline ENF & Enflasyon & TCMB EVDS \\
\hline
\end{tabular}

Kullanılan bütün seriler CENSUS-X12 yöntemi ile mevsimsellikten arındırılmış ve CDS, D ile ENF serileri logaritmik olarak analizde dahil edilmiştir. Değişkenler arasındaki eşbütünleşme ilişkisi için ARDL sınır testi kullanılmıştır.

\subsubsection{ARDL Yaklaşımı}

Çalışmada Ng-Perron birim kök testi sonucunda değişkenlerin I(0) ve I(1)'de birim kök içermedikleri tespit edilmiştir. ARDL yaklaşımı, değişkenlerin farklı düzeylerde durağan oldukları (I(0) ve I(1)) durumlarda değişkenler arasındaki ilişkinin araştırılabileceğini varsaymaktadır. Bununla birlikte bu yöntemin küçük örneklerde daha etkili olması ile kısa ve uzun dönem dinamiklerinin aynı anda dikkate alınıyor (Yamak ve Erdem, 2017: 165) olması nedeniyle Pesaran, Shin ve Smith (2001)'nin geliştirdiği ARDL yaklaşımı kullanılmıştır. ARDL testinde değişkenlerin durağanlık seviyelerinin farklı olması gerekmektedir (Bulut ve Çizgici Akyüz, 2020: 14).

ARDL yaklaşımı üç temel bölüm ile gerçekleştirilmektedir. İlk aşamada, F istatistiği ile eşbütünleşmeye bakılmakta ve ilişki ortaya konulmaktadır. İkinci aşamada uzun dönem ARDL modeli kurulmakta ve uzun dönem katsayılarına ulaşılmaktadır. Üçüncü aşamada hata düzeltme modeli tahmin edilerek kısa dönem katsayılarına ulaşılmaktadır (Terzi ve Akbulut Bekar, 2019: 22). Uygun gecikme uzunluğu bilgi kriterleri ile ilk aşamada elde edilmekte, kısıtlanmamış hata düzeltme modeli ortaya konulmaktadır. (5) no'lu denklem Kısıtsız Hata Düzeltme modeline dayalı sınır testini vermektedir.

$$
\begin{gathered}
\Delta F I K_{t}=\beta_{0}+\beta_{1} \text { Trend }+\beta_{2} F_{I K_{t-1}}+ \\
\beta_{3} C D S_{t-1}+\beta_{4} D_{t-1}+\beta_{5} F_{t-1}+ \\
\beta_{6} E N F_{t-1}+\sum_{i=1}^{q} \delta \Delta F I K_{t-i}+ \\
\sum_{i=1}^{m} \alpha \Delta C D S_{t-i}+\sum_{i=1}^{n} \lambda \Delta D_{t-i}+ \\
\sum_{i=1}^{k} \varphi \Delta F_{t-i}+\sum_{i=1}^{p} \phi \Delta E N F_{t-i}+u_{t}
\end{gathered}
$$

Değişkenlere ait optimal gecikme uzunluklarını (5) no'lu denklemde q, m, n, k ve p ile gösterilmektedir. $\mathrm{Bu}$ denklemde bilgi kriterlerine göre en düşük değeri veren model en uygun modele ulaşılmaktadır.

En uygun ARDL modelinde değişkenler arasında ilişkiyi test etmek amacıyla $\mathrm{F}$ testi yapılmaktadır. (5) no'lu denklemde sıfır hipotezi $\left(\mathrm{H}_{0}: \mu i=\sigma \mathrm{i}=0\right)$ değişkenler arasında eşbütünleşmenin olmadığını, alternatif hipotez $\left(\mathrm{H}_{1}: \quad \mu i \neq \sigma \mathrm{i} \neq 0\right)$ ise değişkenler arasında eşbütünleşmenin olduğunu göstermektedir. Çalışmada gözlem sayısı 48'dir. Bu nedenle Wald testiyle elde edilen $\mathrm{F}$ istatistiği, Narayan (2005) tablo alt kritik değer I(0) ve üst kritik 
değer I(1) ile karşılaştırılmaktadır. F istatistiğinin, I(1) üst sınırdan büyük olması eşbütünleşmenin olduğunu; I(0) alt sınırdan küçük olması eşbütünleşmenin olmadığını; I(0) ile I(1) arasında bulunması eşbütünleşmenin tanımsızlığını belirtmektedir (Akbulut Bekar ve Terzi, 2018: 67).

F istatistiği ile eșbütünleșme tespit edildikten sonra (6) no'lu ARDL (q, m, n, k ve p) modeli ile uzun dönem katsayılarına ulaşılmaktadır.

$$
\begin{gathered}
F I K_{t}=\beta_{0}+\beta_{1} \text { Trend }+\sum_{i=1}^{q} \delta F I K_{t-i}+ \\
\sum_{i=1}^{m} \alpha C D S_{t-i}+\sum_{i=1}^{n} \lambda D_{t-i}+ \\
\sum_{i=1}^{k} \varphi F_{t-i}+\sum_{i=1}^{p} \phi E N F_{t-i}+u_{t}
\end{gathered}
$$

Denklemde $\mathrm{q}, \mathrm{m}, \mathrm{n}, \mathrm{k}$ ve $\mathrm{p}$ optimal gecikme uzunluklarını, $\beta$ katsayıyı göstermektedir (Yamak ve Erdem, 2018: 339). Kurulan modelinin istikrarlılığı ve uygun olup olmadı $\breve{g}$ için diagnostik testler yapılmaktadır. Diagnostik testlerden sonra kurulan ARDL modelinden türetilen Hata Düzeltme modeli kısa dönem katsayılarını vermektedir. (7) no'lu denklemde hata düzeltme modeli verilmiștir.

$$
\begin{gathered}
\Delta F I K_{t}=\alpha_{0}+\beta_{1} \text { Trend }+\sum_{i=1}^{q} \delta \Delta F I K_{t-i}+ \\
\sum_{i=1}^{m} \alpha \Delta C D S_{t-i}+\sum_{i=1}^{n} \lambda \Delta D_{t-i}+ \\
\sum_{i=1}^{k} \varphi \Delta F_{t-i}+\sum_{i=1}^{p} \phi \Delta E N F_{t-i}+ \\
\tau E C T_{t-1}+u_{t}
\end{gathered}
$$

Bu denklemde $\tau E C T_{t-1}$ hata düzeltme terimini göstermektedir. $\quad \tau E C T_{t-1} \quad$ katsayısının işaretinin negatif ve istatistiksel olarak anlamlı bulunması gerekmektedir.

\subsection{Bulgular}

Analiz kapsamında gerçekleştirilen birim kök testi ve ARDL sınır testi sonuçlarına bu başlıkta yer verilmiştir.

\subsubsection{Birim Kök Testinin Sonuçları}

2009:Q1-2020:Q4 dönemi esas alınan çalışmada gerçekleștirilen Ng-Perron birim kök testlerine ilișkin sonuçlar Tablo 2'de

\begin{tabular}{|c|c|c|c|c|c|c|c|c|}
\hline \multirow{3}{*}{$\begin{array}{c}\text { Değişken } \\
\text { FIK }\end{array}$} & \multicolumn{8}{|c|}{ Ng-Perron } \\
\hline & \multicolumn{4}{|c|}{ Sabitli } & \multicolumn{4}{|c|}{ Sabitli-Trendli } \\
\hline & -9.277 (b) & $-2.153(b)$ & 0.232 (b) & 2.643 (b) & -11.027 & -2.332 & 0.211 & 8.343 \\
\hline CDS & -4.952 & -1.566 & 0.316 & 4.965 & -7.506 & -1.922 & 0.256 & 12.170 \\
\hline D & 0.499 & 0.213 & 0.427 & 17.044 & -7.833 & -1.807 & 0.230 & 12.058 \\
\hline $\mathbf{F}$ & -3.059 & -1.230 & 0.402 & 7.995 & -5.008 & -1.581 & 0.315 & 18.191 \\
\hline ENF & 1.619 & 1.144 & 0.706 & 42.416 & -2.104 & -0.768 & 0.365 & 30.528 \\
\hline$\Delta$ FIK & -6.944 & -1.759 & 0.253 & 3.889 & -8.823 & -2.080 & 0.235 & 10.402 \\
\hline$\Delta \mathrm{CDS}$ & -7.521 (c) & $-1.923(c)$ & 0.255 (c) & 3.314 (c) & -20.181 (b) & $-3.036(b)$ & 0.150 (b) & 5.349 (b) \\
\hline$\Delta \mathbf{D}$ & -22.799 (a) & -3.369 (a) & 0.147 (a) & 1.096 (a) & -22.660 (b) & -3.361 (b) & 0.148 (b) & 4.046 (b) \\
\hline$\Delta \mathrm{F}$ & -17.000 (a) & -2.645 (a) & 0.155 (a) & 2.398 (a) & -156.007 (a) & -8.797 (a) & 0.056 (a) & 0.690 (a) \\
\hline$\Delta \mathrm{ENF}$ & -18.765 (a) & -2.998 (a) & 0.159 (a) & 1.538 (a) & $-21.901(b)$ & -3.307 (b) & 0.151 (b) & 4.172 (b) \\
\hline
\end{tabular}
verilmiştir. Tablo 2'de FIK serisinin Ng-Perron birim kök testinde seviyesinde durağan olduğu, CDS, D, F ve ENF serilerinin seviyelerinde birim kök içerdiği, ancak birinci farklarında durağan olduğu sonucu görülmektedir.

Tablo 2: Ng-Perron Birim Kök Testi Sonuçları

Not: a, b ve c sırasıyla \%1, \%5 ve \%10 anlamlılık düzeylerini ifade etmektedir. Ng-Perron tablo kritik değerleri sabitli modelde \%1'de anlamlı - 13.80, $-2.58,0.17,1.78 ; \% 5$ 'te anlaml $-8.10,-1.98,0.23,3.17 ; \% 10$ 'da anlaml $-5.70,-1.62,0.27,4.45$. Sabitli - trendli modelde sirasiyla $\% 1$ 'de anlaml $-23.80,-3.42,0.14,4.03 ; \% 5$ 'te anlaml $-17.30,-2.91,0.16,5.48, \% 10$ 'da anlaml $-14.20,-2.62,0.18,6.67$.

\subsubsection{ARDL Sınır Testi Sonuçları}

FIK ile CDS, D, F ve ENF değişkenleri arasındaki eşbütünleşmeyi tespit etmek için ARDL yaklaşımı kullanılmıștır. Analizde Eviews 10 programı kullanılmıştır. Bağımlı değişsen FIK'ın kullanıldığı denklemde ARDL(7, 1, 2, 3, 3) en uygun model olarak belirlenmiștir. Analiz sonucunda elde edilen $F$ istatistiği ile ilgili sonuçlar Tablo 3'te verilmiştir. Tablo 3'teki kritik değerler, Narayan (2005) çalışmasındaki sabitli model Case (V)'teki $\mathrm{k}=4$ ve $\mathrm{n}=48$ durumuna ait değerlerdir.

Tablo 4'teki F istatistiğinin 11.948 olduğu görülmektedir. 48 gözlem değerinin bulunduğu çalışmada elde edilen F istatistiği Narayan tablo kritik değeri üst sınırından daha yüksek çıkmıştır. Elde edilen bulgulara göre $\mathrm{H}_{0}$ hipotezi reddedilmekte, $\mathrm{H}_{1}$ hipotezi ise kabul 
edilmektedir. $\mathrm{Bu}$ sonuç finansal kırılganlık ile kredi temerrüt takası, döviz kuru, faiz oranı ve enflasyon değişkenlerinin eşbütünleşik olduğunu göstermektedir. İlişki tespit edildikten sonra ARDL modeli ile uzun dönem katsayılarına ulaşılmıştır. ARDL $(7,1,2,3,3)$ için diagnostik testler yapılmış ve ulaşılan bulgular Tablo 4'te verilmiştir.

Tablo 3: ARDL $(7,1,2,3,3)$ Sinır Testi Sonuçları

\begin{tabular}{|ccc|}
\hline \multicolumn{3}{|c|}{ Model: FIK = f (CDS, D, F, ENF) } \\
\hline Test İstatistiği & Değer & k \\
\hline F İstatistiği & $\mathbf{1 1 . 9 4 8}$ (a) & $\mathbf{4}$ \\
\hline $\begin{array}{c}\text { Kritik Değer } \\
\text { Sınırları }\end{array}$ & Düşük I(0) & Yüksek I(1) \\
\hline $\mathbf{\% 1 0}$ & 3.24 & 4.35 \\
\hline $\mathbf{\% 5}$ & 3.83 & 5.06 \\
\hline $\mathbf{\% 1}$ & 5.18 & 6.68 \\
\hline
\end{tabular}

Not: a, \%1 anlamlılık düzeyini ifade etmektedir. Case V: Kısıtlı Sabitli ve Trendli.

Tablo 4'te CDS, D, F ve ENF değişkenlerinin katsayılarının işaretleri pozitiftir ve CDS ile $\mathrm{F}$ değişkenleri istatistiksel olarak \%1'de, D ile ENF değişkenleri ise istatistiksel olarak \%5'de anlamlı olup ve iktisadi açıdan beklenen yönde işarete sahip oldukları görülmektedir.

Diğer bir ifade ile bu değişkenler ile finansal kırılganlık arasında uzun dönemde pozitif bir ilişki bulunmaktadır. Bu sonuç, Türkiye'de kredi temerrüt takası, döviz kuru, faiz oranı ve enflasyonun, finansal kırılganlığ etkilediğini göstermektedir. Dolayısıyla kredi risk priminin artması, döviz kurunun yükselmesi, faiz oranının ve enflasyon oranının artması finansal sistem üzerinde olumsuz bir etkiye, bu da finansal kırılganlığın artışına neden olmaktadır. Ayrıca modele ilişkin yapılan normallik, değișen varyans ve otokorelasyon testlerinde herhangi bir sorun olmadığ ve kurulan ARDL $(7,1,2,3,3)$ modelinin sorunsuz olduğu tespit edilmiştir.

Tablo 4: ARDL (7, 1, 2, 3, 3) Modeli Uzun Dönem Katsayıları

\begin{tabular}{|l|c|c|c|}
\hline Değişkenler & Katsayı & t-İstatistiği & Anlamlılık \\
\hline Uzun Dönem Katsayıları & & & \\
\hline CDS & 0.947009 & 4.758683 & 0.0001 \\
\hline D & 9.924318 & 2.292454 & 0.0335 \\
\hline F & 0.135475 & 7.373995 & 0.0000 \\
\hline ENF & 18.14497 & 2.853323 & 0.0102 \\
\hline C & -37.21223 & -2.238114 & 0.0374 \\
\hline @TREND & -0.087732 & -2.730982 & 0.0133 \\
\hline Tanısal Test Sonuçları & & Test İstatistikleri & Anlamlılık \\
\hline Breusch-Godfrey LM Testi & & 0.2328 & 0.6352 \\
\hline Breusch-Pagan-Godfrey Değişen Varyans Testi & & 0.6475 & 0.8329 \\
\hline Jarque-Bera (Normallik Testi) & & 0.3070 & 0.8576 \\
\hline
\end{tabular}

CUSUM ve CUSUMSQ yapısal testleri kurulan denklemin istikrarlı olup olmadığını göstermektedir. Şekil 1'de bant dışına taşan herhangi bir gözlem olmadığı dolayısıyla eğrilerin \%5 güven aralıklarının dıșına taşmadığı görülmektedir. Buna göre incelenen dönemde yapısal kırılmanın bulunmadığı ve uzun dönem katsayılarının istikrarlı olduğu görülmektedir (Çizgici Akyüz ve Atukalp, 2019: 192). 

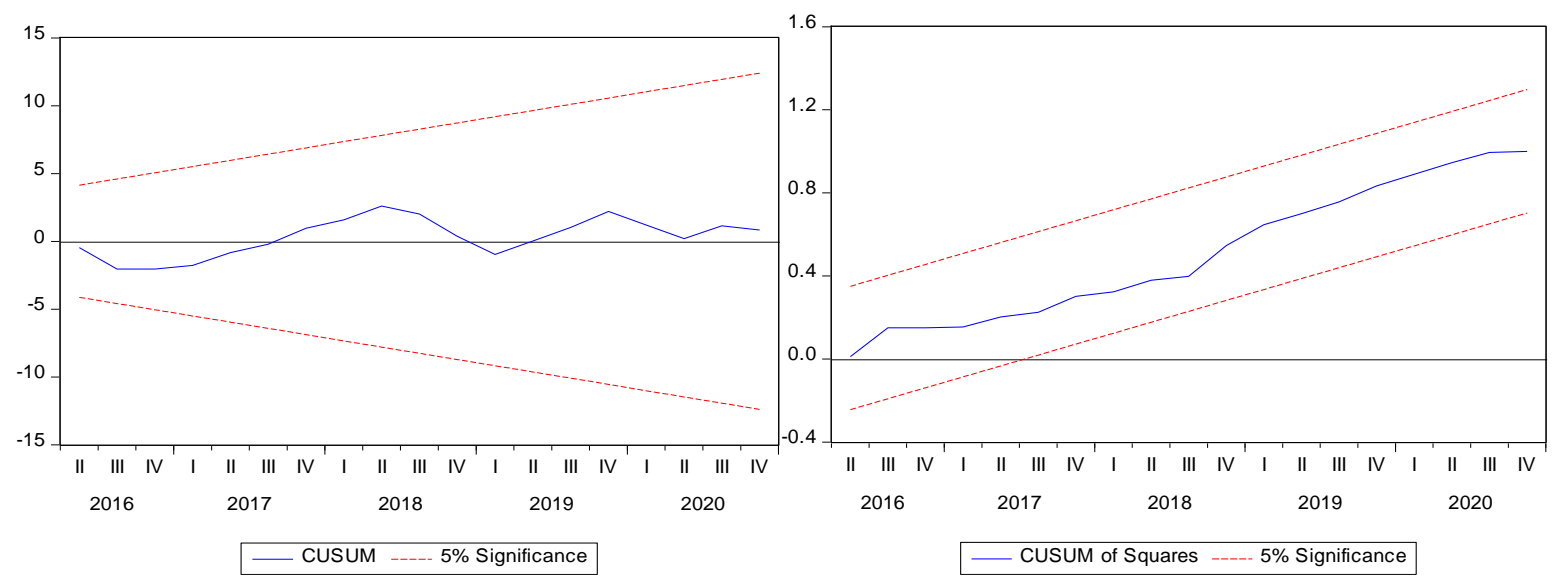

Şekil 1: ARDL $(7,1,2,3,3)$ CUSUM ve CUSUMSQ

Tablo 5'te en uygun ARDL modeli üzerinden tahmin edilen denklemde hata düzeltme modeline ait kısa dönem katsayılar bulunmaktadır. D(CDS), D(D) ve D(ENF) değişkenlerinin kısa dönem katsayılarının pozitif ve $\% 1$ 'de anlamlı olduğu ve iktisadi olarak beklenen yönde bir işarete sahip oldukları görülmüștür. Bu sonuç CDS, D ve ENF değişkenler ile finansal kırılganlık arasında kısa dönemde de pozitif bir ilişki olduğunu göstermektedir. Dolayısıyla yüksek kredi risk primi, yüksek döviz kuru ve yüksek enflasyon Türkiye'de finansal kırılganlığın artırmasına neden olmaktadır. Kısa dönemde D(F) değişkenine ait katsayının anlamsız olduğu görülmekte ve mevduat faiz oranları ile finansal kırılganlık arasında kısa dönemde bir ilișkinin olmadığı șeklinde yorumlanmaktadır. Hata düzeltme modelinde elde edilen $\mathrm{ECT}_{\mathrm{t}-1}$ hata düzeltme katsayısının -0.586 olduğu, $\% 1$ 'de anlamlı bulunduğu tespit edilmiştir. $\mathrm{Bu}$ katsayısının -1'den küçük olması, kısa dönemde meydana gelen sapmaların takip eden dönemlerde giderildiği ve uzun dönem denge durumuna yaklaşma olduğunu göstermektedir.

Kredi temerrüt takası, döviz kuru, faiz oranı ve enflasyonun finansal kırılganlığını artırması bulgusu, teorik beklentilerle uyumludur. Kredi riskinin artması CDS priminin artmasına sebep olmakta, CDS primi vasıtası ile gözlemlenebilen ülke riskinin de risk algısını ve beraberinde finansal kırılganlığı artırması söz konusu olmaktadır.
Tablo 5: Hata Düzeltme Modeli

\begin{tabular}{|l|c|c|c|}
\hline $\begin{array}{c}\text { Bağımsız } \\
\text { Değişken }\end{array}$ & Katsayı & $\begin{array}{c}\mathbf{t}- \\
\text { İstatistiği }\end{array}$ & Anlamlılık \\
\hline $\mathrm{C}$ & -37.21223 & -8.544898 & 0.0000 \\
\hline @TREND & -0.087732 & -8.134237 & 0.0000 \\
\hline $\mathrm{D}(\mathrm{ENF})$ & 16.06930 & 4.547623 & $\mathbf{0 . 0 0 0 2}$ \\
\hline $\mathrm{D}(\mathrm{F})$ & -0.015370 & -1.584554 & 0.1296 \\
\hline $\mathrm{D}(\mathrm{F}(-1))$ & -0.062784 & -3.735678 & 0.0014 \\
\hline $\mathrm{D}(\mathrm{CDS})$ & 0.207811 & 2.930596 & $\mathbf{0 . 0 0 8 6}$ \\
\hline $\mathrm{D}(\mathrm{CDS}(-1))$ & -0.207098 & -2.543600 & 0.0198 \\
\hline $\mathrm{D}(\mathrm{CDS}(-2))$ & -0.211686 & -3.045415 & 0.0067 \\
\hline $\mathrm{D}(\mathrm{D})$ & 3.111763 & 4.902485 & $\mathbf{0 . 0 0 0 1}$ \\
\hline $\mathrm{D}(\mathrm{D}(-1))$ & -4.165369 & -4.517059 & 0.0002 \\
\hline $\mathrm{D}(\mathrm{D}(-2))$ & -1.772658 & -1.823294 & 0.0840 \\
\hline $\mathrm{ECT} \mathrm{t}_{-1}{ }^{*}$ & -0.586484 & -8.503953 & 0.0000 \\
\hline
\end{tabular}

Not: *: Hata düzeltme katsayısı

\section{SONUÇLAR}

Finansal kırılganlık, finansal ve ekonomik krizin meydana gelebilmesine neden olabilecek bir finansal sistemin kırılganlığını göstermektedir. $\mathrm{Bu}$ nedenle finansal olarak kırılgan yapılar bankacilık sisteminin zayıflamasina neden olabilmektedir. Ekonominin tamamını da etkileyecek finansal krizlerin finansal sisteme etkilerini azaltmak amacıyla finansal kırılganlığın ölçülmesi ve kırılganlığı etkileyen faktörlerin belirlenmesi önemlidir. Bu doğrultuda bu çalışmanın amacı, Türkiye'de kredi temerrüt takası, reel efektif döviz kuru, faiz oranı ve enflasyonun finansal kırılganlık üzerine etkisini belirlemektir.

Çalışmada, Türkiye'de finansal kırılganlık ile kredi temerrüt takası, döviz kuru ve enflasyon 
arasındaki ilişki 2009:Q1-2020:Q4 dönemi için ARDL yaklaşımı kullanılarak araştırılmıştır. Analiz sonucunda, kredi temerrüt takası, döviz kuru ve enflasyonun hem kisa hem de uzun dönemde Türkiye'deki finansal kırılganlığ pozitif etkilediği, faiz oranının ise sadece uzun dönemde pozitif etkilediği kısa dönemde ise herhangi bir etkisinin olmadığı tespit edilmiştir.

Literatürde incelenen çalışmalar ele alındığında bu çalışmanın sonuçları, yüksek enflasyonun varlığının krizlere neden olduğunu ve enflasyonun finansal kırılganlığı artıran, faiz oranlarının ise sektörel soruna yol açan bir unsur olduğunu belirleyen Demirgüç Kunt ve Detragiache (1997)'nin çalışmasının sonuçları; reel döviz kuru ve enflasyon ile kırılganlık endeksi arasında pozitif ilişki belirleyen Demirel ve diğerleri (2016)'in çalışmasının sonuçları; kredi riskinde meydana gelen artışın finansal kırılganlığı artırdığını belirten Kaya ve Köksal (2018)'ın çalışmasının sonuçları ve enflasyonun kırılganlığın nedeni olduğunu belirleyen Şimşek ve diğerleri (2019)'nun çalıșmasının sonuçları ile ele alınan değișkenler bazında benzer doğrultudadır.

Bankacılık sektörü merkezli kırılganlıklar, finansal sistemin bütününe yayllabilmekte ve reel sektör üzerinde olumsuz etkilere sebep olmaktadırlar. Döviz kurunda meydana gelebilecek büyük bir değişiklik reel sektör tarafından sahip olunan kur riskinin bankalara yayılmasına neden olabilmekte ve bu da kur riskine bağlı olarak döviz kuru artışının, bankacılık sektöründe bilançoların bozulmasına ve kırılganlıkta artışa sebep olabilmektedir. Döviz kuru istikrarsızlığının ekonomileri krizlere karşı kırılgan hale getiren faktörler arasında yer almasının yanı sıra yüksek enflasyonun yüksek ekonomik kırılganlığı yansıttığı kabul edilmektedir. Enflasyon da ülke ekonomisine yönelik risk artışına neden olabileceğinden kırılganlığı arttırabilecektir. Faiz oranındaki artış ise borçlanmada neden olacağı artış ve yatırımın nakit akışlarının şimdiki değerini düşürmesi noktasında finansal kırılganlığı artırabilmektedir.

\section{KAYNAKÇA}

Akbulut Bekar, S., ve Terzi, H. (2018). Türkiye'de Yurtiçi Tasarruflar ve Ekonomik Büyüme Arasındaki İlişki. Anadolu Üniversitesi Sosyal Bilimler Dergisi, 18(3), 6176.

Akkaya, M., ve Kantar, L. (2019). Bankacıllk Kırılganlık Endeksinin Logit-Probit Model ile Analizi: Türkiye Uygulaması. (650), 131-145.

Andrews, C., ve Flores, M. (2008). Improving Food Crisis Responses in Fragile States. UNUWIDER Research Paper No. 2008/42, https://www.wider.unu.edu/sites/default/ files/rp2008-42.pdf (20.04.2021)

Balıkçığlu, N. (2020). Makroekonomik Kırılganlığın Ölçülmesi: Balkan Ülkeleri ve Türkiye Için Karşılaştırmalı Bir Analiz. MANAS Sosyal Araştırmalar Dergisi, 9(3), 1573-1588.

Bozkurt, İ. (2015). Finansal istikrar ile CDS Primleri Arasındaki Ilişkinin Bulanık
Regresyon Analizi Ile Tespiti: Türkiye Örneği. Gümüşhane Üniversitesi Sosyal Bilimler Elektronik Dergisi, 6(13), 64-80.

Bölükbaşı, Ö. F., Ürkmez E., ve Karamustafa, 0. (2018). Türk Bankacılı Sektörünün Kırılganlı̆̆ı: Ampirik Bir Çalışma. Uluslararası İktisadi ve İdari İncelemeler Dergisi, 18. EYİ Özel Sayısı, 485-496.

Brandon, K., ve Fernandez, F. (2005). Financial Innovation and Risk Management: An Introduction to Credit Derivatives. Journal of Applied Finance, 15 (1), 52-63. https://ssrn.com/abstract $=780726$ (18.04.2021)

Bulut E., ve Çizgici Akyüz, G. (2020). Türkiye'de Dijital Bankacılık ve Ekonomik Büyüme Ilişskisi. Marmara Üniversitesi İktisadi ve İdari Bilimler Dergisi, 42(2), 1-24. 
Çakmak, U. (2013). Finansal kirlganlık Endeksi (Türkiye 1989-2011) ve Yorumlar. Uludağ Üniversitesi İktisadi ve İdari Bilimler Fakültesi Dergisi, 32(1), 239-260.

Çizgici Akyüz, G., ve Akbulut Bekar, S. (2021). The Relationship Between Credit Default Swap and Macroeconomic Indicators: An Example from Turkey. Contemporary Studies in Economic and Financial Analysis, (Ed. Grima, S., Özen, E., ve Boz, H.), Bingley: Emerald Publishing Limited Volume 106, 165-177.

Çizgici Akyüz, G., ve Atukalp, M. E. (2019). Bankaya Özgü Değişkenler ile Kârlılık İlişskisi: Türkiye Örneği. Researches in Economics, Econometrics \& Finance, (Ed. Yıldız, H., ve Aybar, A. S.), London: IJOPEC Publication No: 2019/23, 181-195.

Demirel, B., Barışık, S., ve Karanfil, N. (2016). Türk Bankacılık Sektörü Kırılganlık Endeksini Belirleyen Faktörler. Bankacılar Dergisi, (99), 16-36.

Demirgüç Kunt, A., ve Detragiache, E. (1997). The determinants of banking crises: evidence from developing and developed countries. IMF Working Papers.

Erdoğdu, A. (2019). Türk Bankacılık Sektöründe Finansal Kırılganlık Incelemesi. Arel Üniversitesi İktisadi ve İdari Bilimler Fakültesi Dergisi Ekonomi, Yönetim ve Sosyal Araştırmalar Dergisi, 4(2), 2-13.

Fielding, D., ve Rewilak, J. (2015). Credit Booms, Financial Fragility and Banking Crises. Economics Letters, 136, 233-236.

Grabel, I. (1997). Speculation-led Development in the Third World, Dynamics of Globalization and Development. Recent Economic Thought Series II, (Ed. Gupta, S. D., ve Choudry, N. K.), US: Springer, 111-133.

Göktaş Ö. (2008). Türkiye Ekonomisinde Bütçe Açığının Sürdürülebilirliğinin Analizi. İstanbul Üniversitesi İktisat Fakültesi Ekonometri ve İstatistik Dergisi, 8, 45-64.

Iftikhar, S. F. (2015). Financial Reforms and Financial Fragility: A Panel Data Analysis.
International Journal of Financial Studies, 3, 84-101.

International Monetary Fund (1998). Financial Crises: Characteristics and Indicators of Vulnerability, 74-97. https://www.imf.org/ / media/Websites/IMF/imported-flagshipissues/external/pubs/ft/weo/weo0598/pdf/ _0598ch4pdf.ashx (20.04.2021)

Karabıyık, L., ve Anbar, A. (2006). Kredi Temerrüt Swapları ve Kredi Temerrüt Swaplarının Fiyatlandırılması. Muhasebe ve Finansman Dergisi, (31), 1-11.

Kaya, E., ve Köksal, Y. (2018). Bankacılık Sektörü Finansal Kırılganlı̆̆ı ve Kredi Riski Ilişkisi Üzerine Bir Uygulama. Human society and education in the changing world, (Ed. Yllmaz, E., ve Sulak, S. A.), Konya: Palet Yayınları.

Kinda, T., Mlachila, M., ve Ouedraogo, R. (2016). Commodity Price Shocks And Financial Sector Fragility. IMF Working Papers.

Klomp, J., ve Haan, J. H. (2015). Bank Regulation and Financial Fragility in Developing Countries: Does Bankstructure Matter? Review of Development Finance, 5, 8290.

Lagunoff, R., ve Schreft, S. L. (2001). A Model of Financial Fragility. Journal of Economic Theory, 99, 220-264.

Mete, M., Pekmez, G., ve Kıyançiçek, C. (2016). 2008 Finans Kirizinin Kırılgan Sekizliler Üzerindeki Etkisi: Teorik Bir İnceleme. Elektronik Sosyal Bilimler Dergisi, 15(57), 689-709.

Minsky, H. P. (1995). Sources Of Financial Fragility: Financial Factors in the Economics of Capitalism. Hyman P. Minsky Archive, Paper 69. http://digitalcommons.bard.edu/hm archive/69 (20.04.2021)

Narayan, P. K. (2005). The Saving and Investment Nexus for China: Evidence from Cointegration Tests. Applied Economics, 37(17), 1979-1990. 
Ng, S., ve Perron, P. (2001). Lag Length Selection and the Construction of Unit Root Tests with Good Size and Power. Econometrica, 69(6), 1519-1554.

Penas, M. F., ve Tümer Alkan, G. (2010). Bank Disclosure and Market Assessment of Financial Fragility: Evidence from Turkish Banks' Equity Prices. Journal of Financial Services Research, 37(2), 159-178.

Pesaran, M. H., Shin, Y., ve Smith, R. J. (2001). Bounds Testing Approaches to the Analysis of Level Relationships. Journal of Applied Econometrics, 16(3), 289-326.

Rinaldi, L., ve Sanchis-Arellano, A. (2006). Household Debt Sustainability What Explains Household Non-Performing Loans? An Empirical Analysis. European Central Bank Working Paper Series No. 570, https://papers.ssrn.com/sol3/papers.cfm?ab stract_id=872528 (17.04.2021)

Şimşek, N., Hazar, A., ve Babuşçu, Ş. (2019). Türkiye'nin Finansal Kırılganlığına Etki Eden Makro Ekonomik Faktörler. Ekonomi ve Finansal Araștırmalar Dergisi, 1(1), 48-74.

Terzi H., ve Akbulut Bekar, S. (2019). Türkiye'de Doğrudan Yabancı Yatırımlar, Turizm Ve Dışa Açıklık Arasındaki Ilişki: 19742014 Dönemi. Doğuş Üniversitesi Dergisi, 20(1), 15-30.

Tokucu, E. (2012). Hyman Minsky'nin Finansal Istikrarsızlık Hipotezi Çerçevesinde Finansal Krizler ve Çözüm Önerileri. Ankara Üniversitesi SBF Dergisi, 67(2), 189-212.

Topaloğlu, E. E. (2018). Bankalarda Finansal Kırılganlığı Etkileyen Faktörlerin Panel Veri Analizi ile Belirlenmesi. Eskișehir Osmangazi Üniversitesi İİBF Dergisi, 13(1), 15-38.

Türkiye Cumhuriyet Merkez Bankası (2021). Reel Efektif Döviz Kuru, https://www.tcmb. gov.tr/wps/wcm/connect/tr/tcmb+tr/main+ menu/istatistikler/doviz+kurlari/reel+efektif +doviz+kuruu (05.04.2021)
Yamak, R., ve Erdem, H. F. (2017). Uygulamalı Zaman Serisi Analizi (1. Baskı). Trabzon: Celepler Matbaa Yayın ve Dağıtım. 